\title{
USO DE NOVAS TECNOLOGIAS DIGITAIS PARA DISSEMINAÇÃO DO ENSINO DA CORROSÃO E PROTEÇÃO ANTICORROSIVA
}

\author{
Caroline Sousa dos Santos Xavier \\ Coordenadora de Marketing e Cursos na Associação Brasileira de Corrosão (ABRACO). \\ https://orcid.org/0000-0002-6307-0511
}

Data de submissão: 29/04/2021

Data de aprovação: 09/06/2021

\section{RESUMO}

O presente artigo aborda a implementação de cursos de Ensino à Distância (EaD) com o uso de novas tecnologias digitais da informação e comunicação (TDIC) na qualificação profissional durante a pandemia da COVID-19. Tendo como objetivo avaliar o uso das novas tecnologias digitais na adaptação de um curso na temática de Pintura Industrial da modalidade presencial para o EaD, aplicado pela coordenação de cursos de uma associação brasileira, durante o período de março de 2020 a março de 2021 . Diante do objetivo foi elaborada uma pesquisa exploratória, com a utilização de uma pesquisa de opinião para capturar dados sobre a eficácia do novo método de EaD. Um novo método foi implementado com sucesso em oito turmas alcançando a eficácia desejada. A Associação Brasileira de Corrosão (ABRACO) identificou um conjunto de vantagens, principalmente relacionadas a operacionalização e a qualidade dos cursos realizados. A pesquisa possibilitou concluir que a adaptação da modalidade de ensino presencial para o EaD confirmou a eficácia do uso das novas tecnologias da informação para auxiliar na disseminação de conhecimentos relativos à qualificação profissional no âmbito da indústria nacional.

Palavras-chave: TDIC; qualificação profissional; ensino à distância.

\section{NEW DIGITAL TECHNOLOGIES USE TO CORROSION AND ANTICORROSIVE PROTECTION DISSEMINATION}

\section{ABSTRACT}

The present article addresses the implementation of Distance Learning courses with the use of new digital information and communication technologies (DICT) in professional qualification during the COVID-19 pandemic. The objective is to evaluate the use of new digital technologies in the adaptation of a course on the subject of Industrial Painting from the classroom modality to EaD, applied by the coordination of courses of a Brazilian association, during the period from March 2020 to March 2021. In view of the objective, an exploratory research was designed, using an opinion poll to capture data on the effectiveness of the new EaD method. A new method was successfully implemented in eight classes achieving the desired effectiveness. The Brazilian Association of Corrosion (ABRACO) identified a number of advantages, mainly related to the operationalization and quality of the courses held. The research made it possible to conclude that the adaptation of the face-to-face teaching modality for EaD confirmed the effectiveness of using new 
information technologies to assist in the dissemination of knowledge related to professional qualification within the national industry.

Keywords: DICT; professional qualification; distance learning.

\section{EL USO DE LAS NUEVAS TECNOLOGÍAS DIGITALES PARA LA DIFUSIÓN DE LA ENSEÑANZA DE LA CORROSIÓN Y LA PROTECCIÓN ANTICORROSIVA}

\section{RESUMEN}

El presente artículo aborda la implementación de cursos a distancia con el uso de nuevas tecnologías digitales de la información y la comunicación (TDIC) en la cualificación profesional durante la pandemia de COVID-19. Tiene como objetivo evaluar el uso de las nuevas tecnologías digitales en la adaptación de un curso de la asignatura de Pintura Industrial de la modalidad presencial a la Educación a Distancia (EaD), aplicada por la coordinación de cursos de una asociación brasileña, durante el periodo de marzo de 2020 a marzo de 2021. De cara al objetivo se elaboró una investigación exploratoria, con el uso de una encuesta de opinión para captar datos sobre la eficacia del nuevo método EaD. Se aplicó con éxito un nuevo método en ocho clases, logrando la eficacia deseada. La Asociación Brasileña de Corrosión (ABRACO) identificó un conjunto de ventajas, principalmente relacionadas con la operatividad y la calidad de los cursos realizados. La investigación permitió concluir que la adaptación de la modalidad de enseñanza presencial para la EaD confirmó la eficacia del uso de las nuevas tecnologías de la información para ayudar a la difusión de los conocimientos relacionados con la cualificación profesional dentro de la industria nacional.

Palabras clave: TDIC; cualificación profesional; aprendizaje a distancia.

\section{INTRODUÇÃO}

Trazemos neste trabalho o problema que foi estudado e investigado sobre implementação em curto espaço de tempo de curso de EaD e trouxemos a metodologia que foi aplicada que nos permitiu alcançar o resultado com as metas e objetivos traçados pelos professores envolvidos para adaptação do processo de ensino-aprendizagem da Disciplina corrosão e proteção anticorrosiva.

O objetivo geral foi explorar e avaliar algumas soluções de tecnologias digitais da informação e comunicação disponíveis no mercado para apoiar a transição do processo de ensino-aprendizagem da modalidade presencial para EaD dos cursos da ABRACO.

A Associação Brasileira de Corrosão (ABRACO) é uma entidade sem fins lucrativos, fundada em outubro de 1968 com a missão de "difundir e desenvolver o conhecimento da corrosão e da proteção anticorrosiva, contribuindo para que a sociedade possa garantir a integridade de ativos, proteger as pessoas e o meio ambiente dos efeitos da corrosão" (ABRACO, 2021).

Em sua estrutura organizacional está presente a coordenação de cursos, setor responsável por estabelecer a programação anual de cursos em articulação com a comunidade da corrosão, prospectar as necessidades do mercado e da comunidade da corrosão em consonância com orientações da Diretoria Executiva e da Presidência, além 
de planejar, programar e tomar todas as medidas necessárias à realização da programação anual de cursos.

Desde sua fundação, a ABRACO ministrou seus cursos no formato presencial e com o avanço da pandemia da COVID-19 na cidade do Rio de Janeiro (RIO DE JANEIRO, 2020), foi preciso interromper a realização de cursos presenciais e buscar outras formas viáveis para continuar ministrando cursos. Foi preciso rever e repensar toda sistemática de oferta de cursos e o processo de ensino-aprendizagem adaptado a este novo formato de Ensino à Distância.

Em meio a este novo cenário ou "novo normal" - termo criado pelo empresário americano Mohamed El-Erian, em 2009, para falar sobre as consequências da crise econômica mundial daquele período e que desde então (MOREIRA, 2020), esta expressão tem sido usada para se referir a um momento após uma ruptura de grande magnitude -, atrelado ao avanço recorrente das tecnologias digitais da informação e comunicação surge um novo modelo de aprendizagem que proporciona mudanças significativas no processo de comunicação no âmbito da educação, colocando em análise sob uma nova perspectiva a forma como acontece o ensino tradicional em sala de aula. Esta mudança ainda foi mais profunda, pois, abriu um leque de possibilidades para busca e acesso ao conhecimento.

\section{FUNDAMENTAÇÃO TEÓRICA}

O curso para Qualificação de Inspetor de Pintura Industrial Nível 1 é classificado como um curso técnico, com carga horária de oitenta e oito horas e segue as diretrizes da norma brasileira sobre Critérios para qualificação e certificação de inspetores de pintura industrial (ABNT, 2018). Esta norma estabelece os critérios e a sistemática para qualificação e certificação, bem como descreve as atribuições e responsabilidades deste profissional.

O inspetor de pintura industrial é o profissional capacitado a exercer as atividades de controle de qualidade relativas à pintura industrial. Apesar de ser um curso de oitenta e oito horas e abordar assuntos de forte cunho técnico, cerca de setenta e duas horas são dedicadas para as aulas teóricas e dezesseis horas são dedicadas para as aulas práticas.

Foi a partir desta distribuição de carga horária que a ABRACO identificou a possibilidade de transpor a parte teórica deste curso para a modalidade de EaD, mantendo apenas como presencial a carga horária destinada para as aulas práticas.

Durante este curso, o profissional aprende os conhecimentos básicos sobre corrosão; conceituação e esquemas de pintura; conhecimentos básicos de tintas industriais; preparação da superfície; principais métodos de aplicação; esquemas de pintura; inspeção de recebimento e armazenamento de tintas; controle de qualidade; inspeção visual da superfície pintada; documentação; noções de segurança nos serviços de pintura e normas técnicas aplicáveis às atividades de pintura industrial. Dentre todos os temas acima, este artigo aborda somente sobre a corrosão - definição, efeitos e custos.

De acordo com as normas brasileiras (ABNT, 2004), a corrosão é um processo de deterioração que sofrem os materiais, geralmente metálicos, causado pela reação química e/ou eletroquímica com o meio, associado ou não a esforços mecânicos. As Figura 1 e Figura 2 exemplificam a corrosão e seus efeitos. 
Figura 1 - Processo de corrosão avançada

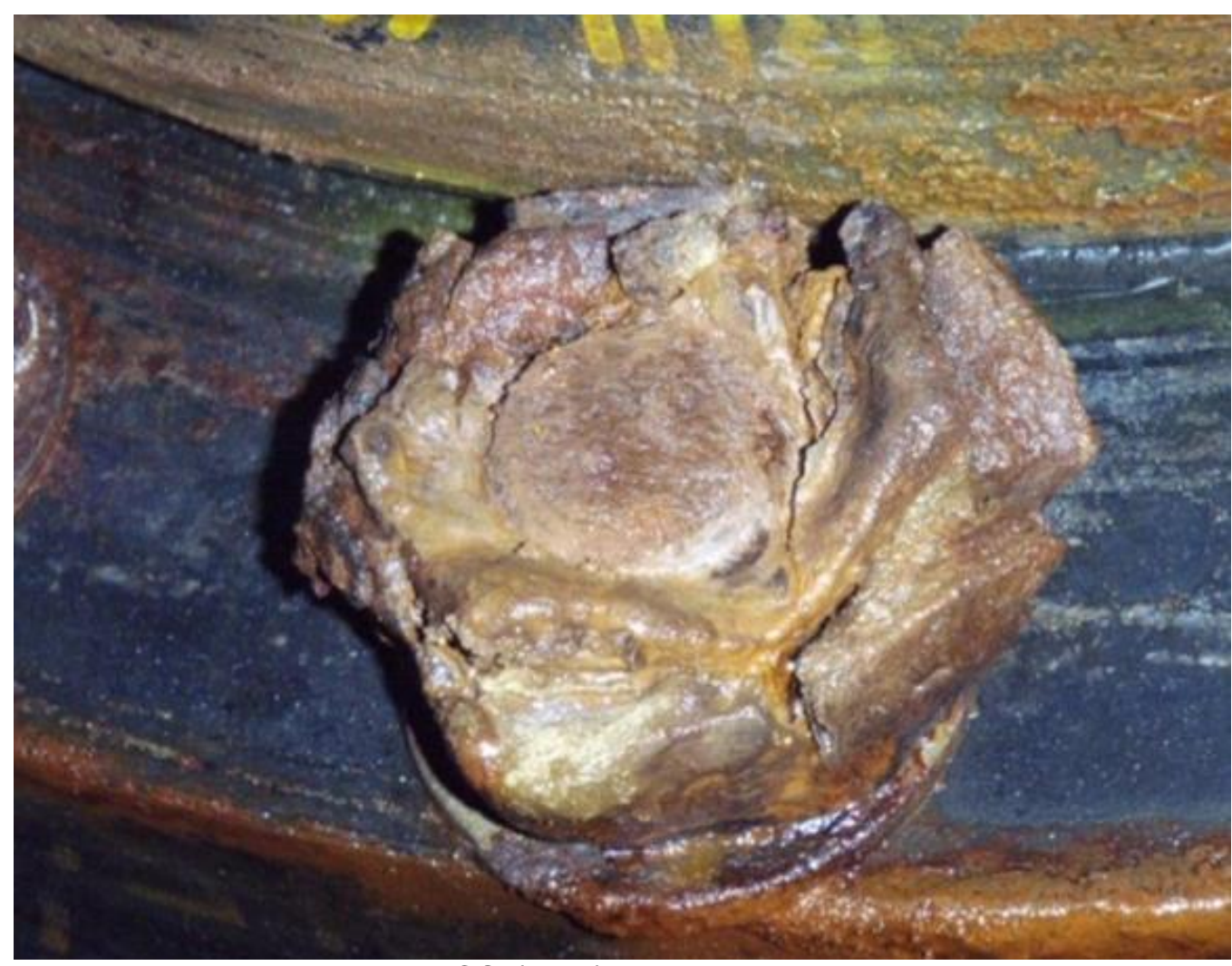

Fonte: Acervo interno da ABRACO (2021).

Figura 2 - Corrosão em zona de variação de maré

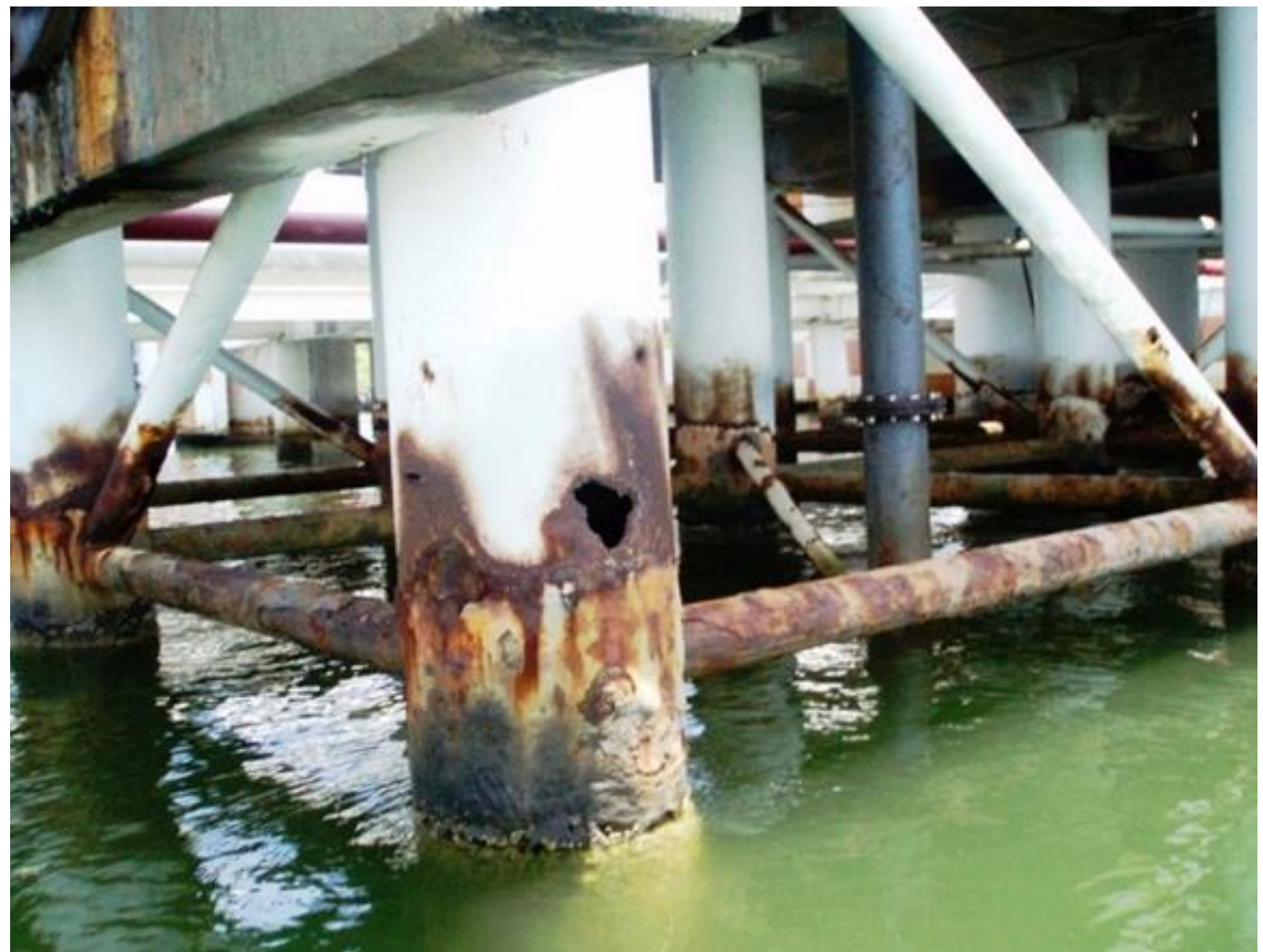

Fonte: Acervo interno da ABRACO (2021). 
Ao falar sobre corrosão, é preciso, inicialmente, entender o campo de estudo aplicado. O estudo da corrosão está baseado no conhecimento prévio dos processos corrosivos dos materiais metálicos e como protegê-los para viabilizar economicamente as instalações industriais construídas com materiais metálicos; manter a vida útil da pintura das estruturas e equipamentos; evitar paradas de processo não programadas e lucros cessantes nas empresas; garantir a segurança dos trabalhadores e a proteção do meio ambiente.

Tratando-se de números, de acordo com um estudo encomendado pelo Congresso Americano realizado de 1999 a 2001 (NACE, 2002), estimou o custo total (direto e indireto) da corrosão da ordem de US\$ 276 bilhões ou 3,1\% do PIB EUA. Este estudo fornece estimativas de custo e identifica estratégias nacionais para minimizar os impactos da corrosão.

Baseado no cenário atual, que se iniciou em março de 2020, muitas incertezas emergiram acerca do futuro: Como se comportaria a economia do país? Como ficaria o mundo após a paralisação geral? As respostas ainda não são claras, mesmo após mais de um ano de pandemia. No entanto, algumas certezas foram observadas e uma delas é que as atividades relacionadas à corrosão não pararam.

A importância da preservação dos ativos para a retomada da economia é de grande importância e as falhas devido a deterioração dos equipamentos e instalações devido à corrosão devem ser tratadas para que as empresas possam retomar suas atividades.

Independente do momento da pandemia, as tecnologias digitais da informação e comunicação já se encontravam cada vez mais presentes no nosso cotidiano, provocando mudanças nas percepções que temos do mundo, nas relações sociais, políticas, econômicas. "A nova geração conectada prefere o papel de protagonista ao de mero espectador do processo. É preciso que os cursos estejam de acordo com essa nova necessidade", como afirmaram Tagarro et al (2019, p. 40).

As relações sociais mudaram devido às novas tecnologias de informação e comunicação e neste viés as instituições vivem um processo de mudança pragmática e, em especial, a educação e o ensino nos diversos níveis (BEHRENS, 2005 apud TAGARRO et al, 2019, p. 40).

Corroborando Xavier et al (2019) afirmam que "o surgimento de novas tecnologias e a internet abriram um horizonte no uso de recursos alternativos no processo de ensinoaprendizagem". E que "sempre que um novo desafio, uma nova proposta ou uma nova situação emerge no trabalho, tal fato nos remete a repensar ou reformular as nossas práticas utilizadas (XAVIER et al, 2019, p. 5).

A ABRACO precisou se reinventar para se adequar às novas exigências do mundo moderno. As adaptações levaram em consideração que a instituição está operando em um cenário com grande difusão de conhecimentos e altamente globalizado, onde as relações de trabalho se modificam intensa e constantemente.

Consequentemente, o ensino profissional deve considerar o cenário em que dos profissionais estão imersos, sendo a educação voltada para a resolução de problemas e desafios reais. Cabendo considerar que neste contexto requer atenção para a escolha do(s) recurso(s) no processo ensino-aprendizagem, pois conforme Lorenzato (1995) afirma que:

Os recursos interferem fortemente no processo de ensino e aprendizagem; o uso de qualquer recurso depende do conteúdo a ser ensinado, dos objetivos que se deseja atingir e da aprendizagem a ser desenvolvida, visto que a utilização de recursos didáticos facilita a observação e a análise de elementos fundamentais para o ensino experimental, contribuindo com o aluno na construção do conhecimento. (LORENZATO, 1995, p. 4).

De acordo com Tagarro et al (2019) "embora as ferramentas TDICs ofereçam oportunidades para uso da EaD, é preciso cuidado na realização do planejamento”, pois" 
existem algumas dificuldades que devem ser consideradas no uso das TDICs. As próprias características dessas tecnologias podem configurar entraves" no decorrer da sua utilização no processo de ensino-aprendizagem.

Visto a importância de se adaptar o estudo da corrosão para a modalidade EaD, é importante destacar a definição do termo EaD:

"Educação a distância é a modalidade educacional na qual alunos e professores estão separados, física ou temporalmente e, por isso, faz-se necessária a utilização de meios e tecnologias de informação e comunicação. Essa modalidade é regulada por uma legislação específica e pode ser implantada na educação básica (educação de jovens e adultos, educação profissional técnica de nível médio) e na educação superior." (MEC, 2021).

\section{METODOLOGIA}

A metodologia adotada foi o Estudo de Caso, sendo uma pesquisa exploratória descritiva de caráter qualitativo, que segundo Zanella (2012, p. 79) "explora a realidade buscando maior conhecimento, para depois planejar uma pesquisa descritiva" que "tem o objetivo de descrever com exatidão os fatos e fenômenos de determinada realidade".

O estudo teve como público alvo os cursistas do Curso Qualificação de Inspetor de Pintura Industrial Nível 1, ofertado pela ABRACO.

A pesquisadora conduziu o trabalho metodológico em 3 fases, tendo contato remotamente com os participantes do curso da ABRACO. O percurso planejado para atingir os objetivos da pesquisa foi implementado em fases sequenciais, descritas a seguir:

Na primeira fase, foi elaborada uma pesquisa exploratória considerando as soluções disponíveis no mercado para transmissão de aulas em tempo real. As avaliações seguiram alguns requisitos, definidos em (WITTEL, 2021), para cada uma das ferramentas/plataformas selecionadas:

- Segurança - a plataforma deve fornecer garantias quanto a segurança dos dados;

- Usabilidade - a plataforma precisa ser intuitiva e fácil de operar;

- Mobilidade - a plataforma deve garantir que o serviço de videoconferência possa ser acessado em qualquer dispositivo conectado à web, com a garantia de segurança e controle de acesso;

- Disponibilidade para diversos sistemas operacionais - a plataforma deve ser disponível para todos os sistemas operacionais, como iOS, Windows, Android e Google, facilitando o acesso;

- Qualidade de áudio - a plataforma deve ser integrada a uma ferramenta de conference call (nome geral pelo qual são conhecidas todas as chamadas das quais participam três ou mais pessoas) potencializando a qualidade do som;

- Compartilhamento de documentos - a plataforma deve dispor da funcionalidade de compartilhamento de arquivos em tempo real;

- Treinamento aos usuários - garantindo a operação da plataforma com eficiência e sem erros; e por último,

- Suporte técnico - a plataforma deve possuir um serviço de suporte técnico para resolução de possíveis falhas e erros no sistema.

Cada requisito analisado recebe um grau de nível de desempenho, baseado na escala Likert (1932):

5 = Muito satisfeito; 4 = Mais ou menos satisfeito; $3=$ Nem satisfeito, nem insatisfeito;

2 = Mais ou menos insatisfeito e 1 = Muito insatisfeito. 
Na segunda fase, após a escolha da ferramenta, foram realizados: treinamentos internos com os professores envolvidos para adaptação do processo de ensinoaprendizagem; alteração do material didático - que antes apenas em formato físico e precisou ser remodelado para o formato digital; adaptação das apresentações (slides) utilizadas pelos professores - com o acréscimo de efeitos e materiais audiovisuais para facilitar o entendimento dos alunos

$\mathrm{Na}$ última fase, após a escolha da ferramenta, treinamento com professores e adaptação do conteúdo didático, conseguimos de fato implementar o Curso de Qualificação de Inspetor de Pintura Industrial Nível 1, na modalidade EaD.

Aplicarmos nos cursos na modalidade EaD a mesma pesquisa de opinião (Questionário - Modelo da ABRACO) realizada nos cursos presenciais junto aos alunos, ilustrado na Figura 3, que foi elaborado com questões básicas e pontuais.

Segundo Mallmann (2009) a "implementação desses questionários gera indicadores concretos sobre a efetividade das estratégias didático-metodológicas planejadas, sobre os materiais didáticos disponibilizados, aproximação e/ou distanciamento das atividades de aprendizagem e avaliações".

Corroborando sobre o tema sobre questionários Cassundé et al. (2016) aborda em sua pesquisa as ferramentas Colles e ATTLS no Moodle, pois são dois tipos de questionários de avaliação de cursos que "permitem diagnósticos mais precisos e sistemáticos a respeito dos interesses, expectativas do grupo de participantes, temas/conteúdos considerados prioritários, grau de interação e interatividades, estratégias de suporte e acompanhamento".

O Colles é abreviação de Constructivist On-Line Learning Environment Survey, (Pesquisa Construtivista do Ambiente de Aprendizagem On-Line) é composto por 24 (vinte e quatro) questões dispostas em 6 (seis) dimensões: 1. Relevância; 2. Reflexão Crítica; 3. Interação; 4. Apoio dos tutores; 5 . Apoio dos colegas; 6 . Compreensão, cada uma relativa a um ponto crucial de avaliação da qualidade do processo de aprendizagem no ambiente virtual (CASSUNDÉ, 2016).

O "fundamento teórico do Colles está pautado pelos princípios de um processo ensino-aprendizagem dinâmico cuja mediação pedagógica acentua as atividades de elaboração conceitual de acordo com a autonomia, interação e cooperação" (MALLMANN, 2009, p. 8 apud CASSUNDÉ et al., 2016, p. 6).

O Colles é uma ferramenta respeitável de avaliação da percepção do aluno, pois abrange diversos pontos importantes na perspectiva de avaliação da aprendizagem, tendo como objetivo avaliar as percepções dos alunos a respeito da relevância da disciplina, da qualidade de interação no ambiente físico e virtual, verificando também se as discussões proporcionam pensamentos críticos e reflexivos, além de avaliar a qualidade do apoio dado pelo docente ao discente e a interação dos discentes entre si (DOUGIAMAS; TAYLOR, 2009; TAYLOR; MAOR, 2000 apud CASSUNDÉ et al., 2016).

ATTLS é abreviação de Attitudes to Thinking and Learning Survey (Pesquisa de Atitudes em relação ao pensamento e à aprendizagem). "Esse questionário se baseia na necessidade de compreender as ações de estudo e aprendizagem desenvolvidas pelos diversos participantes de um curso em termos dos componentes colaborativos e de reflexão crítica diante dos desafios" (CASSUNDÉ, 2016). 
Figura 3 - Modelo de avaliação de treinamento da ABRACO.

1. A carga horária do curso foi satisfatória? *

Marcar apenas uma oval.

Sim

Não

2. A metodologia utilizada (slides, apostilas, módulos e estudos de caso, avaliação prática) foram adequadas? * Marcar apenas uma oval

$\operatorname{Sim}$

Não

3. O conteúdo programático atendeu o objetivo proposto?

Marcar apenas uma oval.

$\operatorname{Sim}$

Não

4. Quanto às provas, foram de fácil compreensão, compativeis ao conteúdo e com o tempo suficiente? * Marcar apenas uma oval.

$\operatorname{Sim}$

Não

Não se aplica a este curso.

5. Desde a inscrição, avalie a atuação da coordenação de cursos? *

Marque todas que se aplicam.

Muito bom

Bom

Regular

Insuficiente

6. Como você avalia o desempenho geral do treinamento nesta escala: *

Marque todas que se aplicam
Muito bom
Bom
$\square$ Regular
$\square$ Insuficiente

Fonte: Próprio autor (2021). 


\section{ANÁLISE E DISCUSSÃO DOS RESULTADOS}

Todos as ferramentas identificadas na pesquisa exploratória foram testadas e analisadas pela equipe interna da ABRACO, em conformidade com os requisitos definidos por Wittel (2021) e a escala Likert (1932) para identificar o nível de desempenho. Dentre as ferramentas disponíveis foram selecionadas: Google Meet, GoToMeeting; Jitsi Meet e Zoom Meeting.

Levado em consideração as pontuações de nível de desempenho em cada requisito analisado, conforme ilustrado na Figura 4, a ferramenta que teve um melhor desempenho e também em relação à custo e benefício foi o Zoom Meeting.

Figura 4 - Requisitos de análise das plataformas.

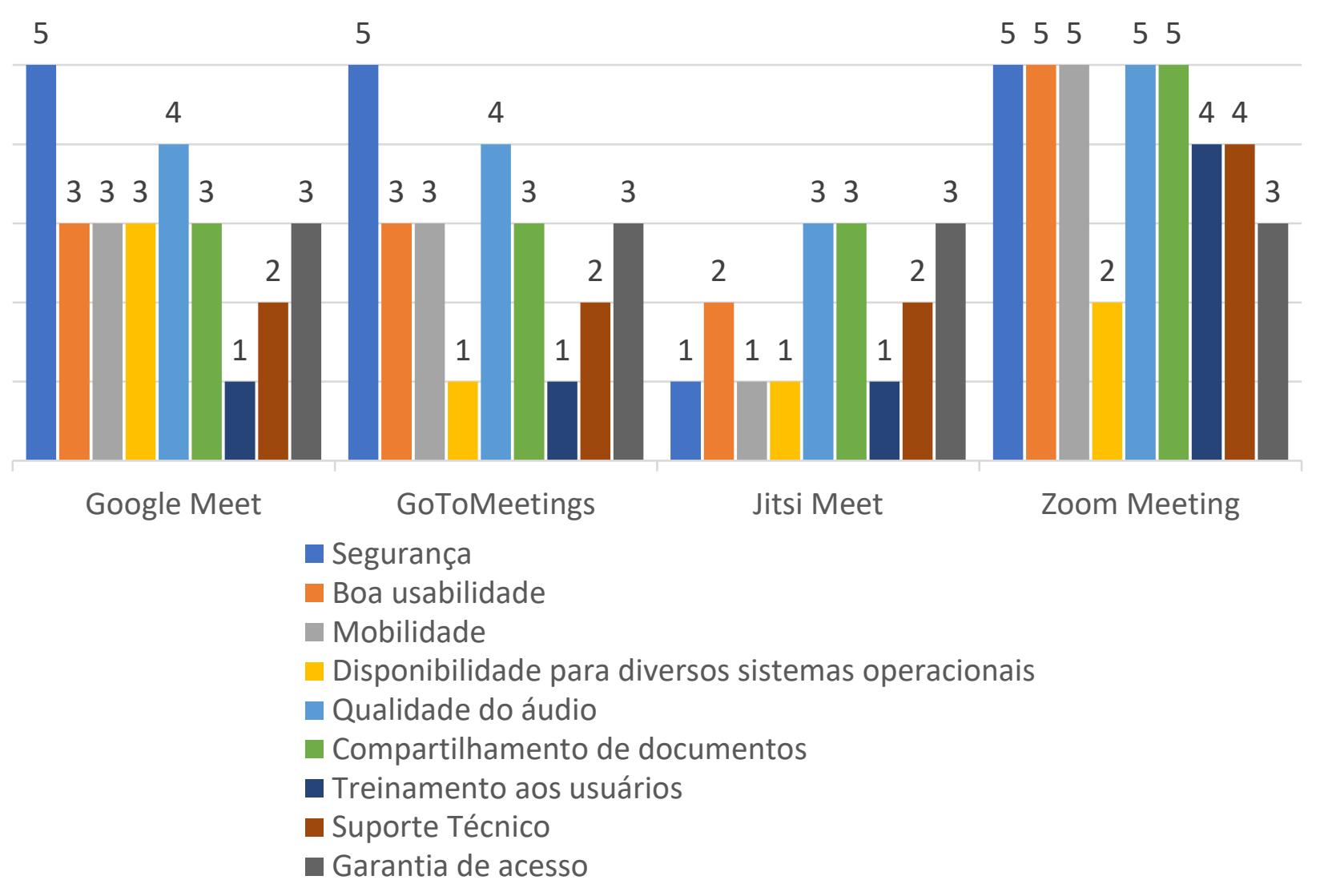

Fonte: próprio autor (2021).

Em seguida, durante os treinamentos internos com os professores, como resultado, houve um processo de adaptação dos materiais didáticos, apresentações (slides), métodos de avaliação, dinâmica de aula, dentre outros.

Durante a execução dessas fases iniciais do percurso metodológico, foi possível identificar algumas dificuldades por parte dos professores devido a não familiarização e domínio de técnicas para a modalidade $\mathrm{EaD}$ em suas rotinas de trabalho. Este cenário começou a mudar, de forma positiva, após vários dias de treinamentos intensivos.

O desafio para os professores foi notório durante o processo de adaptação, envolvendo diversas adaptações, tais como: adaptação ao uso da nova ferramenta; adaptação da dinâmica de aula; alteração do material didático - que antes apenas em formato físico e precisou ser remodelado para o formato digital para viabilizar a distribuição digital e o uso com a utilização de um computador; adaptação das apresentações (slides) utilizadas pelos professores - com o acréscimo de efeitos e materiais audiovisuais para 
facilitar o entendimento dos alunos; e, por fim, revisão do método e critério de avaliação onde foi acrescentado a participação em aula como um fator importante no processo de ensino-aprendizagem.

Por este curso possuir uma carga horária extensa, com quatro horas de aulas diárias durante quatro semanas, foi preciso tornar a aula dinâmica, com a participação de vários professores, momentos dedicados para tirar dúvidas, criação de grupos de estudos através da ferramenta de mensagem (por exemplo: WhatsApp).

Em resumo, foi preciso inovar com apoio das TDIC. É interessante ressaltar que a inovação não está restrita ao uso da tecnologia, mas também à maneira como o professor se apropria desses recursos para criar projetos metodológicos que superem a reprodução do conhecimento e levem à produção do conhecimento (BEHRENS, 2000, p. 103).

Para contar com a participação de alunos nos cursos presenciais era preciso viabilizar os locais de realização dos cursos, como por exemplo em Espírito Santo, Rio de Janeiro, Santa Catarina e São Paulo, conforme detalhado na Quadro 1. Por sua vez, na modalidade EaD não houve esta limitação.

Quadro 1 - Turmas ente janeiro/2019 e novembro/2019.

\begin{tabular}{|c|c|c|c|}
\hline Turma & Local & Mês/Ano & Qtd. Alunos \\
\hline 1 & Rio de Janeiro & Janeiro/2019 & 10 \\
\hline 2 & Rio de Janeiro & Março/2019 & 16 \\
\hline 3 & São Paulo & Abril /2019 & 15 \\
\hline 4 & Rio de Janeiro & Maio /2019 & 06 \\
\hline 5 & Santa Catarina & Maio/2019 & 14 \\
\hline 6 & Rio de Janeiro & Julho/2019 & 19 \\
\hline 7 & Espírito Santo & Agosto/2019 & 17 \\
\hline 8 & Rio de Janeiro & Setembro/2019 & 17 \\
\hline 9 & Rio de Janeiro & Novembro/2019 & 36 \\
\hline \multicolumn{3}{|c|}{ Total de alunos } & 150 \\
\hline
\end{tabular}

Fonte: Próprio autor (2021).

Como resultado, foi observado um aumento significativo no número de alunos, conforme detalhado na Quadro 2, o que representou um sinal positivo de que a modalidade de EaD atingiu os resultados estimados em um curto espaço de tempo.

Quadro 2 - Turmas entre abril/2020 e abril/2021.

\begin{tabular}{|c|c|r|c|}
\hline Turma & Local & \multicolumn{1}{|c|}{ Mês/Ano } & Qtd. Alunos \\
\hline 1 & EaD & Abril/2020 & 11 \\
\hline 2 & EaD & Maio/2020 & 20 \\
\hline 3 & EaD & Junho/2020 & 16 \\
\hline 4 & EaD & Julho/2020 & 25 \\
\hline 5 & EaD & Setembro/2020 & 22 \\
\hline 6 & EaD & Outubro/2020 & 21 \\
\hline 7 & EaD & Novembro/2020 & 28 \\
\hline 8 & EaD & Fevereiro/2021 & 30 \\
\hline 9 & EaD & Abril/2021 & 35 \\
\hline \multicolumn{3}{|c|}{ Total de alunos } & 208 \\
\hline
\end{tabular}

Fonte: Próprio autor (2021). 
Nos cursos na modalidade $\mathrm{EaD}$, houve forte participação e representatividade de alunos de vários estados do Brasil, como: Alagoas, Amazonas, Bahia, Ceará, Espírito Santo, Goiás, Maranhão, Minas Gerais, Pará, Paraná, Rio de Janeiro, Rio Grande do Sul, Santa Catarina e São Paulo.

Além disso, foi formado um time de professores de vários estados para poder participar dos cursos EaD, fator este que era difícil de conciliar na modalidade presencial devido aos altos custos operacionais e de logística.

Outro ponto importante nos cursos EaD foi a flexibilidade do horário e a comodidade do curso. No presencial, o curso era ministrado das oito da manhã às cinco da tarde com duração de duas semanas sequenciais. Em resumo, além do alto investimento e de uma carga horária exaustiva, o aluno precisava ficar um tempo afastado de seu trabalho, e por vezes de sua família, para conseguir concluir o curso durante este período.

No EaD, os cursos são no período noturno, das seis da tarde às dez da noite, com quatro horas diárias de treinamento. Esta carga horária possibilitou a realização do curso fora do horário comercial, fornecendo comodidade e facilidade de acesso aos alunos. Este fator foi um fator diferencial para o aumento da procura do curso de Qualificação de Inspetor de Pintura Industrial Nível 1.

Com o avanço das tecnologias, saber se comunicar através das TDIC se tornou algo essencial para o desenvolvimento profissional. Os cursos EaD representam uma facilidade de acesso, no entanto, ainda há uma grande barreira em relação à inclusão digital.

Segundo (MORAES, 1997), "o simples acesso à tecnologia, em si, não é o aspecto mais importante, mas sim, a criação de novos ambientes de aprendizagem e de novas dinâmicas sociais a partir do uso dessas novas ferramentas".

Para Silva et al. (DE OLIVEIRA et al., 2005 apud SILVA et al., 2016) "a facilidade de uso é crucial no emprego ou não de programas educativos, principalmente por exigirem do estudante atenção aos elementos de interface a serem manipulados para realizar as atividades de aprendizagem".

Neste sentido, a realidade brasileira necessita passar por grandes modificações para permitir o acesso de todos na sociedade da informação.

No final de cada curso presencial e EaD foi executada uma pesquisa de opinião, (Modelo ilustrado na Figura 3). Esta pesquisa avaliou o grau de satisfação dos alunos em relação à metodologia utilizada, aos materiais didáticos, aos professores, ao suporte da coordenação de cursos e a ferramenta para transmissão das aulas em tempo real.

As Figuras 5 e 6, ilustram as respostas dos alunos das turmas presenciais 1,2 e 3 aos questionamentos da pesquisa de opinião. O total de respostas para as turmas presenciais foi de 30 alunos. 

PROTEÇÃO ANTICORROSIVA

Figura 5 - Respostas da pesquisa de opinião (perguntas 1 a 4) - Turmas presenciais.

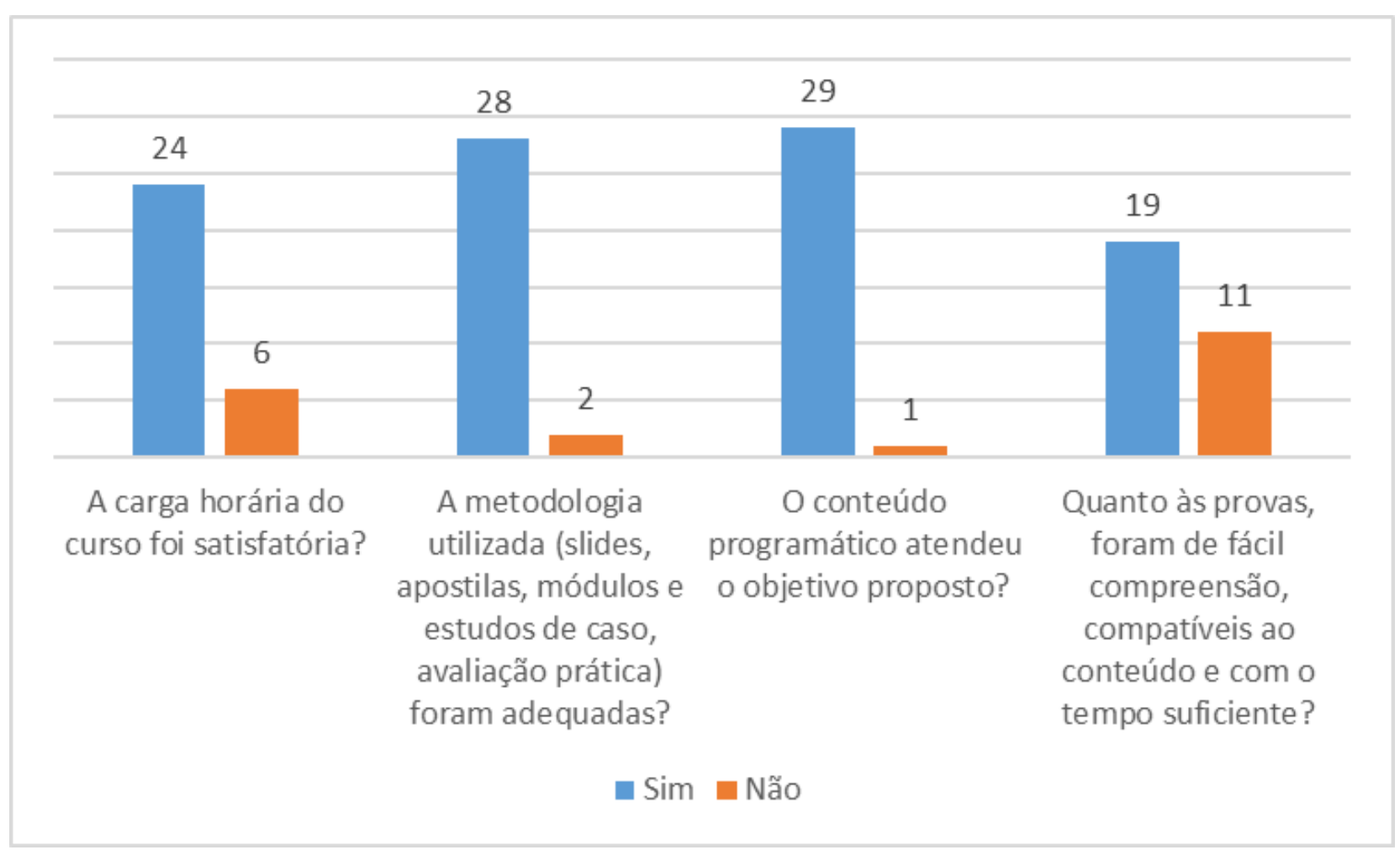

Fonte: Próprio autor (2021).

Figura 6 - Respostas da pesquisa de opinião (perguntas 5 e 6) - Turmas presenciais.

\section{0}

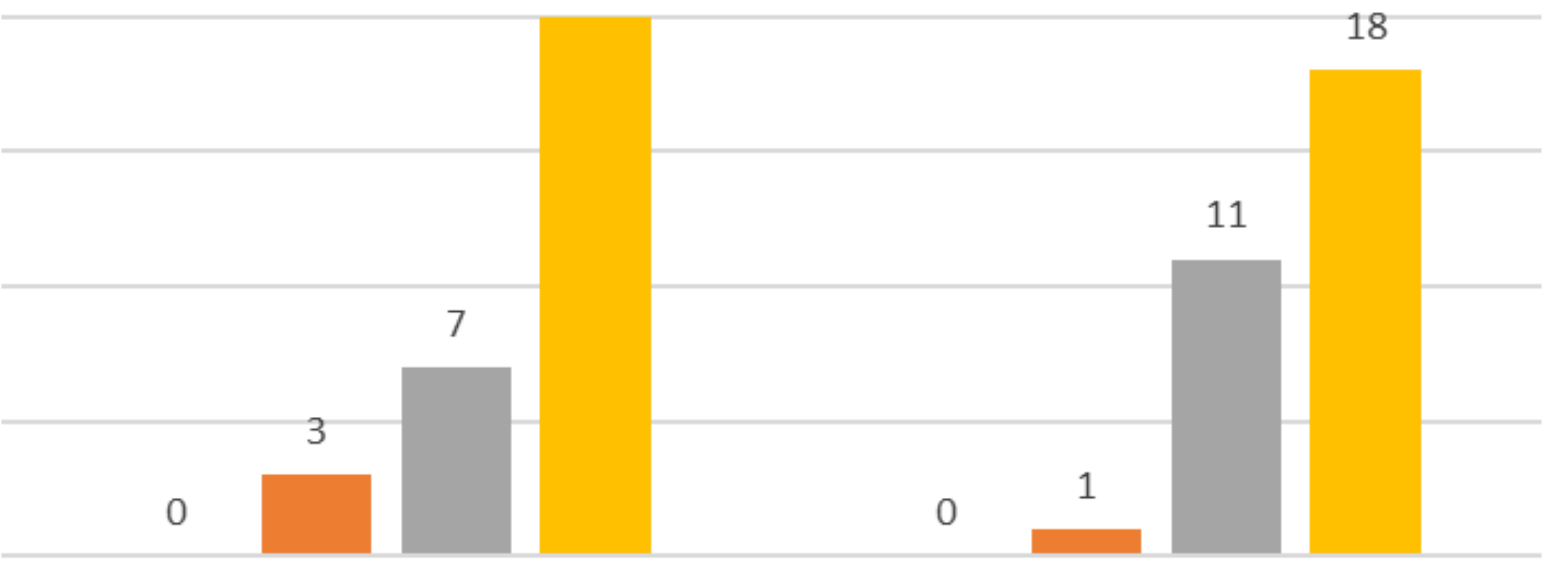

Desde a inscrição, avalie a atuação da coordenação de cursos?
Como você avalia o desempenho geral do treinamento nesta escala:

\section{- Insuficiente $\quad$ Regular Bom $\quad$ Muito bom}

Fonte: Próprio autor (2021).

Por sua vez, as Figuras 7 e 8 ilustram o consolidado das respostas dos alunos das turmas EaD 1, 2 e 3, totalizando 40 respondentes. É importante destacar que o preenchimento da pesquisa de opinião não foi obrigatório. 
Comparando os gráficos das Figuras 5 e 7 é possível observar uma melhora na satisfação dos alunos da modalidade EaD, principalmente em relação a carga horaria e a compreensão das provas.

Esta melhoria em relação a modalidade EaD também é observada na comparação das Figuras 6 e 8, havendo uma melhora na satisfação do papel da coordenação e no desempenho geral do treinamento.

Figura 7 - Respostas da pesquisa de opinião (perguntas 1 a 4)) - Turmas EaD.

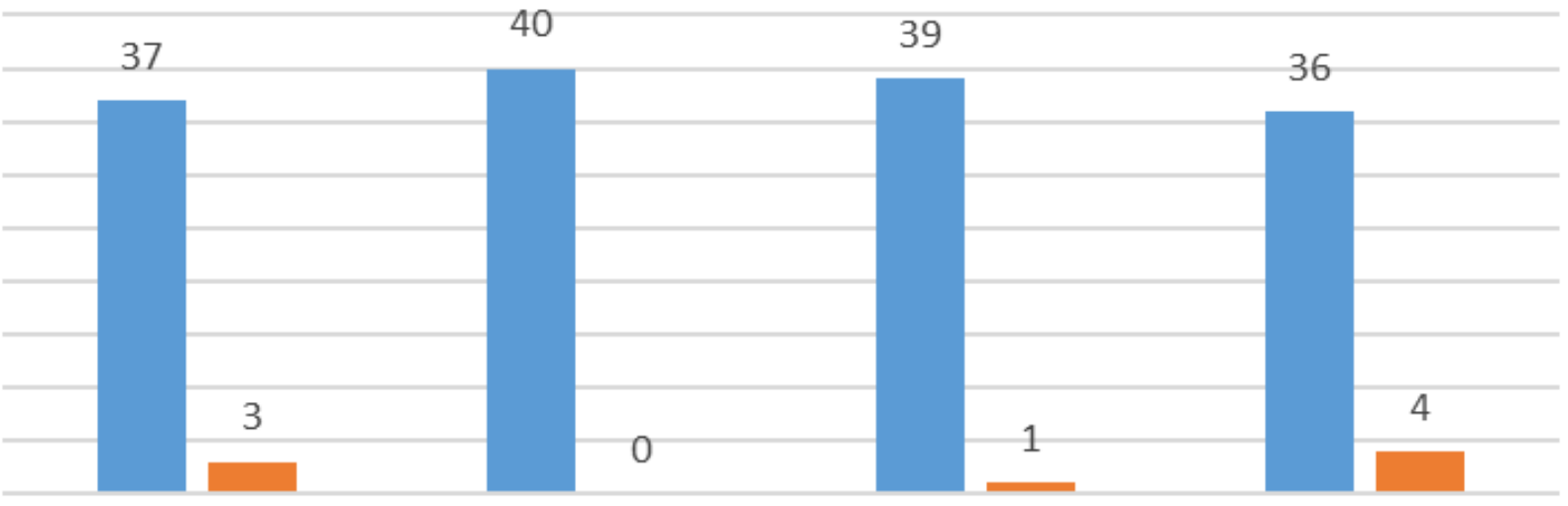
A carga horária do
A metodologia
O conteúdo
curso foi satisfatória?
utilizada (slides,
programático atendeu apostilas, módulos e o objetivo proposto?
estudos de caso,
avaliação prática)
foram adequadas?

Quanto às provas,

foram de fácil

compreensão,

compatíveis ao

conteúdo e com o

tempo suficiente?

— Sim n Não

Fonte: Próprio autor (2021).

Figura 8 - Respostas da pesquisa de opinião (perguntas 5 e 6) - Turmas EaD.

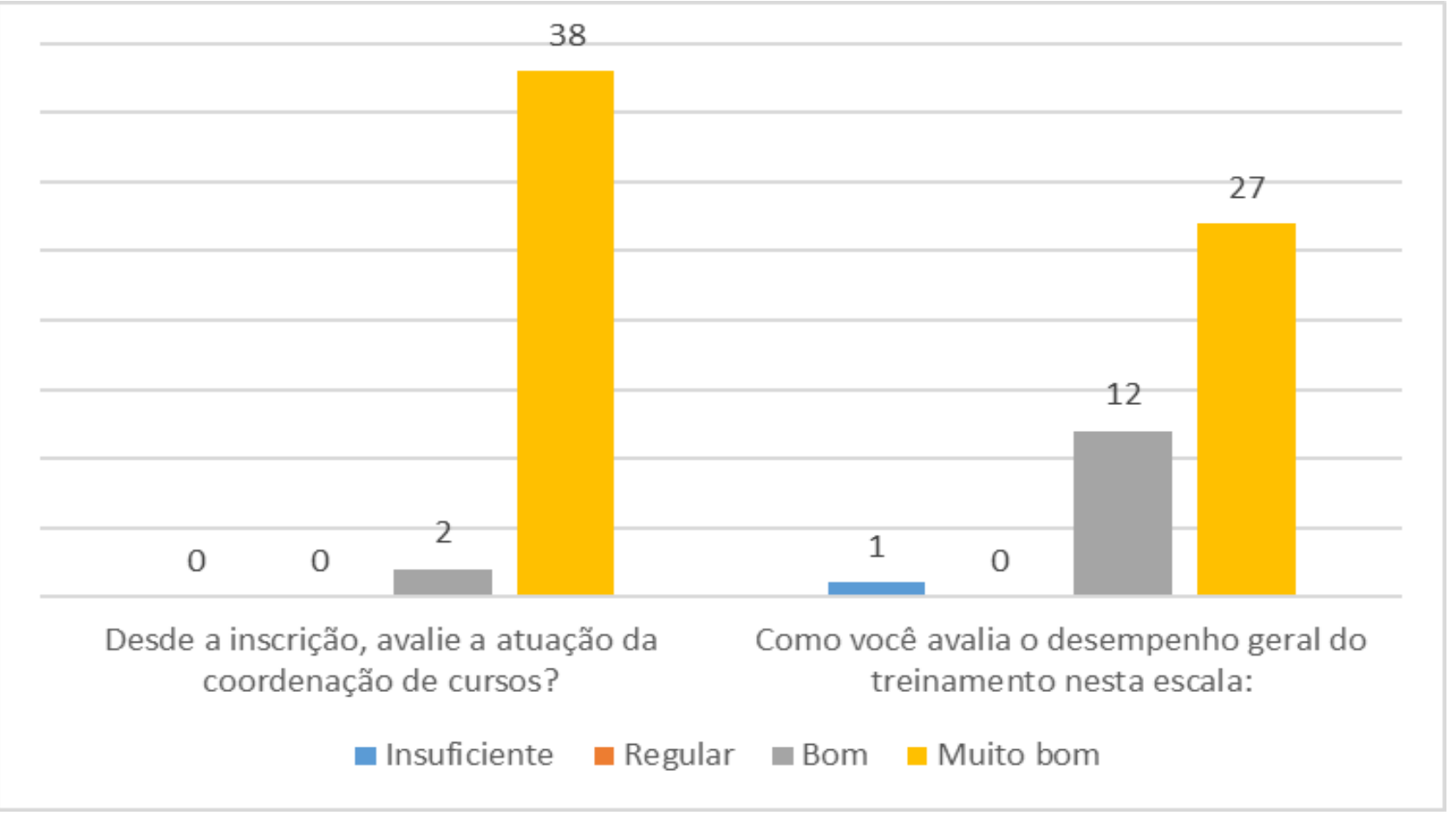

Fonte: Próprio autor (2021). 


\section{CONSIDERAÇOES FINAIS}

O contexto da pandemia da COVID-19 proporcionou mudanças na ABRACO, em especial no curso de Pintura Industrial. A pesquisa possibilitou concluir que a adaptação da modalidade de ensino presencial para o EaD confirmou a eficácia do uso das TDIC para auxiliar na disseminação de conhecimentos relativos à qualificação profissional no âmbito da indústria nacional.

A metodologia adotada atingiu com sucesso os objetivos traçados e viabilizou a implementação com sucesso de 8 (oito) turmas do curso na modalidade EaD, alcançando a eficácia desejada.

A ABRACO pontuou um conjunto de vantagens na implementação do curso EaD, como: flexibilidade do horário das aulas; representatividade de alunos e professores de vários estados do Brasil; facilidade de networking e sociabilização; acompanhamento e suporte da coordenação de cursos possibilitando uma melhor avalição do professor; acompanhamento personalizado para cada aluno; acompanhamento do programa didático e desempenhando um papel motivacional para professores e alunos.

Também foi possível identificar pontos de melhoria para serem trabalhados, tais como: a implementação de um banco de questões para exercícios e provas - contribuindo para o aprendizado e fixação dos conteúdos abordados durantes as aulas EaD; preparação dos alunos para manterem o foco e a concentração durante o curso, pois, a facilidade de fazer o curso em sua residência, por exemplo, requer do aluno uma dedicação e atenção para um melhor aproveitamento do curso; e investimento por parte da ABRACO em novos colaboradores para ajudar no processo de acompanhamento e monitoria dos cursos EaD.

Ao escrever e estudar sobre educação e TDIC é possível entender que ensinar não é uma tarefa simples. Exige preparo, dedicação e, principalmente, método de abordagem eficaz para construir o processo de ensino-aprendizagem.

Espera-se, que com este artigo, seja possível encorajar empresas e profissionais autônomos a investir nos cursos EaD e principalmente entender como as TDIC podem auxiliar durante este processo de implementação, estudo e pesquisa.

Como proposta de trabalhos futuros a Equipe de ABRACO pretende implementar melhorias no questionário de avaliação para os cursos na modalidade $\mathrm{EaD}$, visando maior aderência para algumas das 6 (seis) dimensões da pesquisa construtivista do ambiente de aprendizagem on-line, em especial sobre as questões: Quão relevante é o processo de aprendizagem para a vida profissional do participante? As atividades on-line estimulam os processos de reflexão crítica dos alunos? Até que ponto os diálogos on-line são ricos, considerando um contexto educativo? Em que medida as atividades dos professores favorecem o desenvolvimento de habilidades de participação no curso on-line?

\section{REFERÊNCIAS}

ABNT- Associação Brasileira de Normas Técnicas. NBR 15156:2015: pintura Industrial Terminologia.. Rio de Janeiro: Associação Brasileira de Norma Técnicas, 2004. p. 8.

ABNT- Associação Brasileira de Normas Técnicas. NBR15218: critérios para qualificação e certificação de inspetores de pintura industrial. Rio de Janeiro: Associação Brasileira de Normas Técnicas, 2018.

ABRACO. Associação Brasileira de Corrosão. Institucional. 2021. Rio de Janeiro: ABRACO. Disponivel em: https://abraco.org.br/institucional/. Acesso em: 22 abr. 2021. 
CASSUNDÉ, F. R. et al. Avaliação social construtivista de uma experiência em ead: o uso do COLLES enquanto instrumento de coleta de dados. EAD em Foco - Revista Científica em Educação a Distância, v. 6, n. 2, 2016. Disponível em: https://eademfoco.cecierj.edu.br/index.php/Revista/article/view/339. Acesso em: jun. 2021.

INSIDER. Folha de Londrina. Folha de Londrina, 7 Maio 2020. Disponivel em: https://www.folhadelondrina.com.br/colunistas/consultoria-empresarial/o-que-e-o-novonormal-sobre-o-qual-todo-mundo-fala-2990379e.html.

LIKERT, R. A technique for the measurement of attitudes. Archives of psychology. 1932.

LORENZATO, S. A. Porque não ensinar geometria? Educação Matemática em Revista, Rio de Janeiro, 1995. 3-13.

MEC. O que é educação a distância? Ministério da Educação, 2021. Disponivel em: http://portal.mec.gov.br/escola-de-gestores-da-educacao-basica/355-perguntasfrequentes-911936531/educacao-a-distancia-1651636927/12823-o-que-e-educacao-adistancia. Acesso em: 22 abr. 2021.

MALLMANN, E. M. Gestão de cursos de capacitação em ead: potencialidade das ferramentas de pesquisa e avaliação. In: ABED. CIAED, 15. 2009 . Fortaleza - CE. Disponível em: http://www.abed.org.br/congresso2009/CD/trabalhos/452009163839.pdf. Acesso em: jun. 2021.

MORAES, D. Globalização, midia e cultura contemporânea. 1. ed. [S.I.]: Letra Livre, 1997.

MOREIRA, W. O que é o "novo normal" sobre o qual todo mundo fala? Folha de Londrina, 7 maio 2020. Disponivel em:

https://www.folhadelondrina.com.br/colunistas/consultoria-empresarial/o-que-e-o-novonormal-sobre-o-qual-todo-mundo-fala-2990379e.html. Acesso em: 22 abr. 2021.

NACE. Cost of corrosion study. National Association of Corrosion Engineers, 2002. Disponivel em: https://www.nace.org/resources/general-resources/cost-of-corrosion-study. Acesso em: 22 abr. 2021.

RIO DE JANEIRO. Decreto no 47282, de 21 de março de 2020. Determina a adoção de medidas adicionais, pelo Município, para enfrentamento da pandemia do novo Coronavírus - COVID - 19, e dá outras providências., Rio de Janeiro: Prefeitura, 2020. Disponivel em:

http://www.rio.rj.gov.br/documents/8822216/11086083/DECRETO_47282_2020.pdf. Acesso em: 28 abr. 2021.

SILVA, A. T. da; TEIXEIRA, G. A. P. B.; BARRETO, C. M. B. Avaliação de um ambiente virtual de aprendizagem de imunologia. EAD em Foco - Revista Científica em Educação a Distância, v. 6, n. 2, 2016. Disponível em: https://doi.org/10.18264/eadf.v6i2.381. Acesso em: jun. 2021.

TAGARRO, W. X. et al. Utilização das ferramentas de tecnologias digitais da informação e comunicação pelo professor no ensino superior. RECITE - Revista Carioca de Ciência, Tecnologia e Educação, v. 4, n. 2, p. 39-59, 2019. Disponível em: https://doi.org/10.17648/2596-058X-recite-v4n2-4. Acesso em: mai. 2021. 
XAVIER, M. A. G.; CARVALHO, A. C. de; BRANDÃO, L. P.; FREITAS, V. G. G. A relação entre a formação dos professores e o ambiente virtual de aprendizagem. RECITERevista Carioca de Ciência, Tecnologia e Educação, v. 4, n. 2, 2019. Disponível em: https://doi.org/10.17648/2596-058X-recite-v4n2-1. Acesso em: mai. 2021.

WITTEL. Checklist para escolher a melhor solução de videoconferência. Blog Wittel, 2021. Disponivel em: https://blog.wittel.com/solucao-de-videoconferencia/. Acesso em: 22 abr. 2021.

ZANELLA, L. C. H. Metodologia de estudo de pesquisa em administração. 2.ed. Florianópolis: Departamento de Ciências da Administração / UFSC, 2012. 